\title{
Expression of the glucocorticoid receptor in breast cancer-associated fibroblasts
}

\author{
XAVIER CATTEAU ${ }^{1-3}$, PHILIPPE SIMON ${ }^{2,4}$, FRÉDÉRIC BUXANT ${ }^{5}$ and JEAN-CHRISTOPHE NOËL ${ }^{2,6}$ \\ ${ }^{1}$ Department of Pathology, Tivoli University Hospital-Free University of Brussels, La Louvière; ${ }^{2}$ Department of Pathology, \\ Erasme University Hospital-Free University of Brussels, Brussels; ${ }^{3}$ Institute of Pathology and Genetics, Gosselies; \\ ${ }^{4}$ Gynaecology Unit, Erasme University Hospital-Free University of Brussels; ${ }^{5}$ Gynaecology Unit, \\ Iris South Hospital-Free University of Brussels; ${ }^{6}$ Gynaecopathology Unit, Pathology Department, \\ Erasme University Hospital-Free University of Brussels, Brussels, Belgium
}

Received January 18, 2016; Accepted May 30, 2016

DOI: $10.3892 / \operatorname{mco} .2016 .975$

\begin{abstract}
Cancer- associated fibroblasts (CAFs) are actively involved in breast carcinoma. Our previous study demonstrated that the majority of these CAFs were smooth muscle actin (SMA) positive and were therefore termed peritumoral myofibroblast (PMY). Glucocorticoid, linked or not with its receptor (GR), has been postulated to serve a major role in normal breast and breast carcinoma; however, their role in CAFs remains poorly understood. The aim of the present study was to assess the presence of GR in breast CAFs and particularly in PMY in 56 cases of invasive breast carcinoma in correlation with clinicopathological parameters, by immunohistochemistry. GR was observed in CAFs in 51 cases (91\%) and were more frequent in luminal A subtype (19/19 cases; 100\%). The stromal expression was statistically correlated with the tumor grade $(\mathrm{P}=0.03)$, the Ki-67 index $(\mathrm{P}=0.003)$ and the presence of $\mathrm{GR}$ in the epithelial component $(\mathrm{P}=0.01)$. The demonstration of a frequent expression of GR in breast CAFs may serve as an interesting target for future therapeutics for the regulation of the tumoral breast microenvironment.
\end{abstract}

\section{Introduction}

Glucocorticoids (GCs) are essential for survival and serve a major role in embryonic development, tissue homeostasis and in the regulation of the inflammatory response $(1,2)$. In breast, the functions of GCs are complex and depend, in part, if they are linked to their receptor (GR) and consist of the control of milk secretion, differentiation and apoptosis (3). Morphologically, previous studies have demonstrated that GR

Correspondence to: Dr Xavier Catteau, Department of Pathology, Tivoli University Hospital-Free University of Brussels, Avenue Max Buset 34, B-7100 La Louvière, Belgium

E-mail: xavier.catteau06@gmail.com

Key words: cancer associated fibroblast, peritumoral myofibroblast, glucocorticoid, glucocorticoid receptor, breast carcinoma, stroma nuclear expression is observed both in normal breast, in situ carcinoma and less frequently in invasive carcinoma (4-7). In invasive tumors, their expression is limited in tumors with a small size, low grade, good prognosis and expressing estrogen receptor (ER) (4,7). In addition, our previous study clearly demonstrated that dexamethasone has an antiproliferative effect in the MCF-7 breast cells that express GR (8).

Over previous years, the tumor-associated stroma and, in particular, the cancer associated fibroblasts (CAFs) have been demonstrated to serve a crucial role in cancer pathogenesis $(9,10)$.

Our previous study clearly demonstrated that the majority of these CAFs were smooth muscle actin (SMA)-positive with a myofibroblastic-like phenotype and that the presence of these peritumoral myofibroblasts (PMY) is important both in situ and in invasive breast carcinoma of no special type (11). This is also important in metastatic disease by promoting tumor invasion, growth and angiogenesis through paracrine factors and/or direct cell-cell crosstalk (11-13).

Our previous study demonstrated the presence of ER or progesterone receptors (PR); however, the presence and potential role of GR is poorly understood in breast carcinoma PMYs (4).

Therefore, the present study aimed to assess, by immunohistochemistry, the presence or absence of GR in breast CAFs and in CAFs smooth muscle positive/PMY in correlation with clinicopathological variables. Investigating this may assist with elucidating the role of GR in breast carcinoma.

\section{Materials and methods}

Patient selection. Breast tissue samples were retrieved from the Departments of Pathology at the Erasme Hospital and IRIS South Hospital (Brussels, Belgium), and consisted of 56 cases of invasive carcinoma. The present study was approved by the Ethics Committee from Erasme University Hospital (no. P2014/418).

Immunohistochemistry. The immunohistochemical assessment of ER, PR, Ki-67 and human epidermal growth factor receptor (HER) 2 was routinely performed using an antigen retrieval method using the Leica BOND-III fully automated 


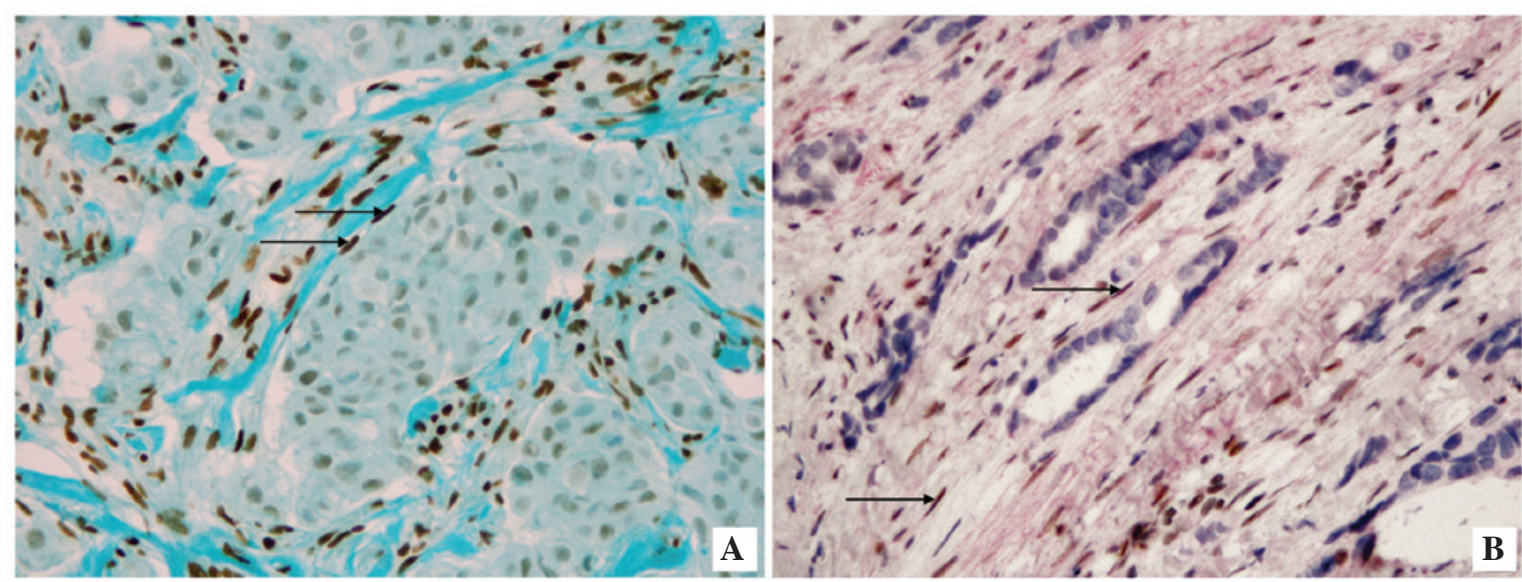

Figure 1. Immunohistochemical staining of CAFs. (A) A typical example of glucocorticoid receptor in CAFs (arrows). Note the strong immunoreactivity score of these cells by comparison with the epithelial carcinomatous component, which is negative (magnification, $\mathrm{x} 10$ ). (B) The double staining immunohistochemistry confirmed the positivity of these nuclear receptors (brown) in $\alpha$-smooth muscle actin positive CAFs/peritumoral myofibroblats stained in red (arrow) (magnification, $\mathrm{x} 40$ ). The immunoreactivity for glucocorticoid receptor is moderate. CAF, cancer associated fibroblast.

system (Leica Microsystems, Ltd., Newcastle, UK), as previously described (4). According to these parameters, carcinoma were divided into five groups, as previously described (14): Luminal A $(n=19)$, Luminal B $(n=12), \operatorname{HER} 2+/ \operatorname{ER}+(n=7)$, HER2+/ER- $(n=9)$ and triple negative $(n=9)$. In addition, the following parameters were also included for each patient: Age, stage, tumoral size and lymph node status. All parameters are shown in the Table I.

For the demonstration of GR, a manual technique was applied. Tissue sections $(4 \mu \mathrm{m})$ were cut sequentially and mounted onto superfrost-treated slides (Menzel-Gläser, Braunschweig, Germany). The slides were dried overnight at $37^{\circ} \mathrm{C}$ prior to deparaffinization in xylene and rehydration through graded ethanols. For epitope retrieval, the slides were immersed in a waterbath at $95-99^{\circ} \mathrm{C}$ for $90 \mathrm{~min}$ with an ethylenediamine tetraacetic acid buffer (pH 9.0; S236; Dako Corp., Glostrup, Denmark). The slides were subsequently cooled in the buffer for $20 \mathrm{~min}$ at room temperature. $\mathrm{H}_{2} \mathrm{O}_{2}(0.3 \%)$ was subsequently added to the slides and incubated for $30 \mathrm{~min}$. The tissues were then incubated for $1 \mathrm{~h}$ with a monoclonal antibody against the N-terminus of the GR (clone 4H2; cat. no. NCL-GCR; 1:25; Novocastra Laboratories, Newcastle, UK) (4).

Double immunostaining. In addition, for the specific visualization of the expression of ER/PR and GR in SMA-positive CAFs, a double stain was also performed by using the EnVision G/2 double stain system (Dako Corp.), as previously described (15). The same monoclonal antibodies (ER, PR and GR) described above were applied to rehydrated paraffin tissue sections and allowed to incubate for $1 \mathrm{~h}$ at room temperature. Endogenous peroxidase was inhibited and 3,3'-diaminobenzidine was used to visualize the binding of these primary antibodies. The sections were subsequently incubated for $1 \mathrm{~h}$ with a secondary antibody against SMA (clone $\alpha \mathrm{SM}-1$; 1:50; Novocastra Laboratories, Newcastle, UK). Alkaline phosphatase-conjugated secondary antibody and fuchsin as substrate chromogen system were used to complete the secondary immunostain. Negative controls used the replacement of the different primary antibodies with the corresponding isotypes. In addition, to ensure the absence of PMY in the normal breast, 10 cases of normal breast tissue from patients who underwent plastic surgery were also included.

Immunohistochemical evaluation. All the slides were examined by two independent observers (Xavier Catteau and Jean-Christophe Noël) and the evaluation of ER, PR and GR was made independently by the two pathologists using the Allred score (16), and estimated the proportion of positive CAFs (0, no positive cells; $1, \leq 1 ; 2,1-10 ; 3,11-33 ; 4,34-66$; $5,67-100 \%$ positive cells) and the average staining intensity ( 0 , negative; 1 , weak; 2 , Intermediate; 3 , strong). The proportion score and the intensity score were added to obtain a total score ranging from $0-8$. Subsequently, three grades of immunoreactivity were established: Score 0-2, negative; score 3-4, weak positivity; score 5-8, strong positivity.

Statistical analysis. The correlation analysis was performed. $\chi^{2}$-test and Fisher's exact test were used. All statistical analyses were performed using XLSTAT software (Addinsoft, Paris, France). $\mathrm{P}<0.05$ was considered to indicate a statistically significant difference.

\section{Results}

Weak or strong expression of GR in CAFs was observed in 10 cases $(18 \%)$ and 41 cases $(73 \%)$, respectively. A total of 5 cases were negative (5\%; Table I). The stromal expression was frequent in luminal A tumor (100\% of cases; Fig. 1A) and is statistically correlated with the tumor grade $(\mathrm{P}=0.03)$, the Ki-67 index $(\mathrm{P}=0.003)$ and GR status in glandular/carcinomatous component $(\mathrm{P}=0.01)$; however, was not correlated with age, tumor size, lymph node status and the expression of ER or PR, at least with a positive status for the latest as $\geq 1 \%$ in accordance with the World Health Organization recommendations (Table I). The double stain immunohistochemistry confirming unequivocally that among these CAFs, SMA-positive PMY clearly showed a nuclear staining of GR (Fig. 1B). 
Table I. Association of clinicopathological characteristics with immunohistochemical levels of GR in the peritumoral stroma.

\begin{tabular}{|c|c|c|c|c|c|}
\hline \multirow[b]{2}{*}{ Characteristic } & \multirow[b]{2}{*}{ No. cases $(\%)$} & \multicolumn{3}{|c|}{ GT expression in the stroma } & \multirow[b]{2}{*}{ P-value } \\
\hline & & Strong & Weak & Negative & \\
\hline Age, years & & & & & 0.56 \\
\hline$\leq 50$ & $24(43)$ & 18 & 5 & 1 & \\
\hline$>50$ & $32(57)$ & 23 & 5 & 4 & \\
\hline Tumor size, mm & & & & & 1 \\
\hline$<20$ & $28(50)$ & 21 & 5 & 2 & \\
\hline$\geq 20$ & $28(50)$ & 20 & 5 & 3 & \\
\hline Stage & & & & & 0.81 \\
\hline $\mathrm{T} 1$ & $28(50)$ & 21 & 5 & 2 & \\
\hline $\mathrm{T} 2$ & $21(37.5)$ & 15 & 3 & 3 & \\
\hline $\mathrm{T} 3$ & $7(12.5)$ & 5 & 2 & 0 & \\
\hline Tumor grade & & & & & 0.03 \\
\hline Grade 1 & $10(17.9)$ & 10 & 0 & 0 & \\
\hline Grade 2 & $22(39.2)$ & 12 & 8 & 2 & \\
\hline Grade 3 & $24(42.9)$ & 19 & 2 & 3 & \\
\hline Lymph node status & & & & & 0.19 \\
\hline Negative & $29(51.8)$ & 24 & 4 & 1 & \\
\hline Positive & $27(48.2)$ & 17 & 6 & 4 & \\
\hline ER status & & & & & 0.64 \\
\hline Negative & $18(32.1)$ & 14 & 2 & 2 & \\
\hline Positive & $38(67.9)$ & 27 & 8 & 3 & \\
\hline PR status & & & & & 0.39 \\
\hline Negative & $23(41.1)$ & 15 & 6 & 2 & \\
\hline Positive & $33(58.9)$ & 26 & 4 & 3 & \\
\hline $\mathrm{Ki}-67$ index, \% & & & & & 0.003 \\
\hline$\leq 14$ & $19(33.9)$ & 19 & 0 & 0 & \\
\hline$>14$ & $37(66.1)$ & 22 & 10 & 5 & \\
\hline HER 2 status & & & & & 0.2 \\
\hline Negative & $40(71.4)$ & 31 & 7 & 2 & \\
\hline Positive & $16(28.6)$ & 10 & 3 & 3 & \\
\hline Intrinsic subtype & & & & & 0.189 \\
\hline Luminal A & $19(33.9)$ & 19 & 0 & 0 & \\
\hline Luminal B/HER2- & $12(21.4)$ & 5 & 5 & 2 & \\
\hline Luminal B/HER2+ & $7(12.5)$ & 4 & 2 & 1 & \\
\hline HER2+ & $9(16.1)$ & 6 & 1 & 2 & \\
\hline Triple negative & $9(16.1)$ & 7 & 2 & 0 & \\
\hline GR status in glands & & & & & 0.01 \\
\hline Negative & $26(46.4)$ & 15 & 6 & 5 & \\
\hline Positive & $30(53.6)$ & 26 & 4 & 0 & \\
\hline
\end{tabular}

$\mathrm{P}$-values in bold are statistically significant $(\mathrm{P}<0.05)$. ER, estrogen receptor; PR, progesterone receptor; HER2, human epidermal growth factor receptor; GR, glucocorticoid receptor.

\section{Discussion}

For numerous years, the majority of studies in breast carcinoma have been focused predominantly on the epithelial component; however, recently CAFs and in particular CAFs SMA-positive PMY have been demonstrated to serve an important role in cancer pathogenesis as a result of paracrine cross-interaction between these and epithelial cancer cells. Indeed CAFs/PMY are able to secrete various factors implicated in invasion, matrix remodeling, cell proliferation, differentiation and apoptosis. In breast carcinoma, the hormonal regulation of epithelial cells is well documented and is the result of interaction 
between estrogen and progesterone, and their respective receptors, at least in hormone-dependent tumor types $(16,17)$. The role of GCs in normal breast is more controversial and likely depends on the balance between targets of linked and non-linked GR with opposing functions: linked GR being involved in maintaining functional differentiation and non-linked GR appearing to be proapoptotic $(3,6)$. In breast carcinoma, the GCs acting through their nuclear receptors are considered as a potential tumor suppressor promoting accurate chromosome segregation during mitosis occurring tumoral cell division $(6,18,19)$. Indeed, according to these data, our previous study demonstrated an antiproliferative effect of dexamethosone in the MCF-7 breast cancer cells line that contains nuclear GR (8). The underlying mechanisms of hormonal regulation of CAFs/PMY remain to be determined; however, our previous study and other previous studies have clearly demonstrated that ER and PR were not present in these cells.

By contrast, the present study clearly demonstrated the presence of a marked GC nuclear immunoreactivity of CAFs in $73 \%$ of cases. In addition, this strong immunoreactivity was demonstrated by double labeling in CAFs SMA-positive PMY (Fig. 1) for the first time, to the best of our knowledge. This strong CAFs immunoreactivity was typically more frequent in luminal A (100\%) compared with in other subtypes. In addition, it appeared to be correlated with different conventional clinicopathological parameters, including the grade $(\mathrm{P}=0.03)$ and Ki-67 index $(\mathrm{P}=0.003)$. The $\mathrm{CR}$ expression in CAFs was also more frequent when these receptors were present in the carcinomatous counterpart $(\mathrm{P}=0.01)$. These data suggested that, as previously shown for matrix metalloproteinase-2, the characteristics and properties of CAFs present in breast carcinoma microenvironment are probably complex and different from one subtype to another (10,20-22).

GCs are considered as agents capable of regulating the proliferation of myofibroblasts in different pathologies where they serve a major role as wound healing or asthma $(23,24)$. Previously, in a myofibroblast cell line associated with colonic carcinoma, dexamethasone inhibited the expression of different classical procarcinogenic factors, including tenascin $\mathrm{C}$, hepatocyte growth factor and transforming growth factor- $\beta$, in a receptor-dependent manner (25).

The present data are interesting since over the last few years it appears that in addition to the development concerning the classical therapies (hormone therapies, chemotherapies and immunotherapies), the peritumoral stroma served as potential target therapy in various carcinomas $(9,24,25)$. Finally, even if it remains hypothetical, it has been postulated that the stress through GCs can be a promoting agent in breast cancer $(26,27)$. From this point of view, demonstrating the presence of GR in the CAFs may be important.

The demonstration of a frequent expression of GR in breast CAFs may serve as an interesting target for future therapy in the regulation of the tumoral breast microenvironment. Naturally, future research is required, firstly to establish with larger cohorts the assocaition between the presence of GR in CAFs and the overall survival, and to understand how a therapy may influence the CAF associated with breast carcinoma. Such investigations are in progress.

\section{Acknowledgements}

The authors would like to thank Mrs. Isabelle Fayt and Mrs. Nadège De Kindt for their excellent technical work. The present study was supported by the Institut de Recherche Scientifique de Pathologie et de Génétique.

\section{References}

1. Hollenberg SM, Weinberger C, Ong ES, Cerelli G, Oro A, Lebo R, Thompson EB, Rosenfeld MG and Evans RM: Primary structure and expression of a functional human glucocorticoid receptor cDNA. Nature 318: 635-641, 1985.

2. Arango-Lievano M, Lambert WM and Jeanneteau F: Molecular biology of glucocorticoid signaling. Adv Exp Med Biol 872: 33-57, 2015.

3. Ritter HD and Mueller CR: Expression microarray identifies the unliganded glucocorticoid receptor as a regulator of gene expression in mammary epithelial cells. BMC Cancer 14: 275, 2014.

4. Buxant F, Engohan-Aloghe C and Noël JC: Estrogen receptor, progesterone receptor, and glucocorticoid receptor expression in normal breast tissue, breast in situ carcinoma, and invasive breast cancer. Appl Immunohistochem Mol Morphol 18: 254-257, 2010.

5. Lien HC, Lu YS, Cheng AL, Chang WC, Jeng YM, Kuo YH, Huang CS, Chang KJ and Yao YT: Differential expression of glucocorticoid receptor in human breast tissues and related neoplasms. J Pathol 209: 317-327, 2006.

6. Vilasco M, Communal L, Mourra N, Courtin A, Forgez P and Gompel A: Glucocorticoid receptor and breast cancer. Breast Cancer Res Treat 130: 1-10, 2011.

7. Abduljabbar R, Negm OH, Lai CF, Jerjees DA, Al-Kaabi M, Hamed MR, Tighe PJ, Buluwela L, Mukherjee A, Green AR, Ali S, et al: Clinical and biological significance of glucocorticoid receptor (GR) expression in breast cancer. Breast Cancer Res Treat 150: 335-346, 2015.

8. Buxant F, Kindt N, Laurent G, Noël JC and Saussez S: Antiproliferative effect of dexamethasone in the MCF-7 breast cancer cell line. Mol Med Rep 12: 4051-4054, 2015.

9. Otranto M, Sarrazy V, Bonté F, Hinz B, Gabbiani G and Desmoulière A: The role of the myofibroblast in tumor stroma remodeling. Cell Adh Migr 6: 203-219, 2012.

10. Gandellini P, Andriani F, Merlino G, D'Aiuto F, Roz L and Callari M: Complexity in the tumour microenvironment: Cancer associated fibroblast gene expression patterns identify both common and unique features of tumour-stroma crosstalk across cancer types. Semin Cancer Biol 35: 96-106, 2015.

11. Catteau X, Simon P, Vanhaeverbeek M and Noël JC: Variable stromal periductular expression of CD34 and smooth muscle actin (SMA) in intraductal carcinoma of the breast. PLoS One 8: e57773, 2013.

12. Catteau X, Simon P and Noël JC: Myofibroblastic stromal reaction and lymph node status in invasive breast carcinoma: Possible role of the TGF- $\beta 1 /$ TGF- $\beta$ R1 pathway. BMC Cancer 14: 499, 2014.

13. Catteau X, Simon P and Noël JC: Myofibroblastic reaction is a common event in metastatic disease of breast carcinoma: A descriptive study. Diagn Pathol 9: 196, 2014.

14. Preat F, Simon P and Noel JC: Differences in breast carcinoma immunohistochemical subtypes between immigrant Arab and European women. Diagn Pathol 9: 26, 2014.

15. Noel JC, Fayt I and Buxant F: Proliferating activity in paget disease of the nipple. Pathol Oncol Res 16: 7-10, 2010.

16. Allred DC, Harvey JM, Berardo M and Clark GM: Prognostic and predictive factors in breast cancer by immunohistochemical analysis. Mod Pathol 11: 155-168, 1998.

17. Senkus E, Kyriakides S, Ohno S, Penault-Llorca F, Poortmans P, Rutgers E, Zackrisson S and Cardoso F; ESMO Guidelines Committee: Primary breast cancer: ESMO clinical practice guidelines for diagnosis, treatment and follow-up. Ann Oncol 26 (Suppl 5): v8-v30, 2015.

18. Mitre-Aguilar IB, Cabrera-Quintero AJ and Zentella-Dehesa A: Genomic and non-genomic effects of glucocorticoids: Implications for breast cancer. Int J Clin Exp Pathol 8: 1-10, 2015.

19. Matthews LC, Berry AA, Morgan DJ, Poolman TM, Bauer K, Kramer F, Spiller DG, Richardson RV, Chapman KE, Farrow SN, et al: Glucocorticoid receptor regulates accurate chromosome segregation and is associated with malignancy. Proc Natl Acad Sci USA 112: 5479-5484, 2015. 
20. Rønnov-Jessen L and Bissell MJ: Breast cancer by proxy: Can the microenvironment be both the cause and consequence? Trends Mol Med 15: 5-13, 2009.

21. Karagiannis GS, Poutahidis T, Erdman SE, Kirsch R, Riddell RH and Diamandis EP: Cancer-associated fibroblasts drive the progression of metastasis through both paracrine and mechanical pressure on cancer tissue. Mol Cancer Res 10: 1403-1418, 2012.

22. Powell DW: Myofibroblasts: Paracrine cells important in health and disease. Trans Am Clin Climatol Assoc 111: 271-292; discussion 292-293, 2000.

23. Hinz B, Phan SH, Thannickal VJ, Prunotto M, Desmoulière A Varga J, De Wever O, Mareel M and Gabbiani G: Recent developments in myofibroblast biology: Paradigms for connective tissue remodeling. Am J Pathol 180: 1340-1355, 2012.
24. Grose R, Werner S, Kessler D, Tuckermann J, Huggel K, Durka S, Reichardt HM and Werner S: A role for endogenous glucocorticoids in wound repair. EMBO Rep 3: 575-582, 2002.

25. Drebert Z, Bracke M and Beck IM: Glucocorticoids and the non-steroidal selective glucocorticoid receptor modulator, compound A, differentially affect colon cancer-derived myofibroblasts. J Steroid Biochem Mol Biol 149: 92-105, 2015.

26. Michael YL, Carlson NE, Chlebowski RT, Aickin M, Weihs KL, Ockene JK, Bowen DJ and Ritenbaugh C: Influence of stressors on breast cancer incidence in the Women's Health Initiative. Health Psychol 28: 137-146, 2009.

27. Antonova L, Aronson K and Mueller CR: Stress and breast cancer: From epidemiology to molecular biology. Breast Cancer Res 13: 208, 2011. 